\title{
ANÁLISE DA RELAÇÃo ENTRE PRECIPITAÇÃo E VOLUME DE ÁGUA NAS SUB-BACIAS CONTRIBUINTES PARA O AÇUDE EPITÁCIO PESSOA
}

\author{
ANDRADE, Amanda Ribeiro - a.ribeirodandrade@gmail.com \\ Universidade Federal da Paraíba - UFPB \\ LIMA, Paulo Ricardo Cavalcante- paulo.ricardo.c.lima@gmail.com \\ Universidade Federal da Paraíba - UFPB \\ OLIVEIRA, João Victor Pequeno- victorpokeno@gmail.com \\ Universidade Federal da Paraíba - UFPB \\ LUCENA, Daisy Beserra - daisyblucena@gmail.com \\ Universidade Federal da Paraíba - UFPB
}

\begin{abstract}
RESUMO: O objetivo deste trabalho é analisar a possível relação entre a distribuição espaço-temporal da precipitação nas principais sub-bacias que abastecem o Açude Epitácio Pessoa, com o volume de água armazenado no reservatório. Para tanto, foram utilizados dados de precipitação mensal provenientes da AESA (Agência Executiva de Gestão das Águas do Estado da Paraíba) e do DCA (Departamento de Ciências Atmosféricas) para o período de 1972 a 2016, assim como dados de volume do açude para o mesmo período, também disponibilizados pela AESA. Para a classificação dos anos de eventos de precipitação extrema foi utilizada a técnica dos quantis. Os resultados mostraram que a variação do volume de água do reservatório possui relação com o comportamento da precipitação. No entanto, esta relação oferece apenas uma visão parcial, tendo em vista que o volume armazenado no açude possui influência direta de fatores como a perda de água por evaporação, vazão afluente, vazão efluente, além de elementos indiretos que influenciam na variação destes e que não foram considerados no estudo. No entanto, foi possível identificar que o açude ultrapassou a sua capacidade máxima em um total de 16 anos, e que estes anos foram classificados, a partir da técnica dos quantis, como anos chuvosos e muito chuvosos. Estes resultados sugerem que durante a série em estudo, as oscilações no volume do reservatório podem ser explicadas também pelo clima característico e distribuição espaço-temporal da precipitação da região.
\end{abstract}

Palavras-Chave: Precipitação; Técnica dos Quantis; Açude Epitácio Pessoa; Volume de água; Deficiência Hídrica

ANALYSIS OF THE RELATION BETWEEN PRECIPITATION AND VOLUME OF WATER IN THE SUB-BASINS THAT SUPPLY THE EPITACIO PESSOA WATER RESERVOIR

ABSTRACT: The objective of this work is to analyze the relation between the spatialtemporal distribution of precipitation in the sub-basins which supply the Epitácio Pessoa Dam with the volume of water stored in the reservoir. For that, monthly precipitation data from the EASA (Executive Agency for the Management of the Waters of the State of Paraíba) and the DCA (Department of Atmospheric Sciences) were used for the period from 1972 to 2016, as well as data on the volume of the dam. For the classification of the years of extreme precipitation events, the quantiles technique was used. The results showed that the reservoir water volume variation is related to the precipitation behavior. However, this relationship offers only a partial view, considering that the volume stored in the dam has the direct influence of factors such as evaporation water loss, inflow, effluent flow, and indirect elements that influence the variation and were not considered in the study. However, it was possible to identify that the weed surpassed its maximum capacity for a total of 16 years, and that these years were classified, using the quantil technique, as rainy and very rainy years. These results suggest that during the study series, the oscillations in the volume of the reservoir can be explained also by the 
characteristic climate and the spatio-temporal distribution of the precipitation of the region.

Keywords: Precipitation; Quantiles technique; Epitacio Pessoa dam; Volume; Water Deficiency.

ANÁLISIS DE LA RELACIÓN ENTRE PRECIPITACIÓN Y VOLUMEN DE AGUA EN LAS SUBCUENCAS CONTRIBUYENTES PARA EL AÇUDO EPITÁCIO PESSOA

RESUMEN: El objetivo de este trabajo es analizar la posible relación entre la distribución espacio-temporal de la precipitación en las principales subcuencas que abastecen el Depósito Epitácio Pessoa, con el volumen de agua almacenado en el depósito. Para ello, se utilizaron datos de precipitación mensual provenientes de la AESA (Agencia Ejecutiva de Gestión de las Aguas del Estado de Paraíba) y del DCA (Departamento de Ciencias Atmosféricas) para el período de 1972 a 2016, así como datos de volumen del azud para el período mismo período, también disponibles por la AESA. Para la clasificación de los años de eventos de precipitación extrema se utilizó la técnica de los cuantiles. Los resultados mostraron que la variación del volumen de agua del yacimiento está relacionada con el comportamiento de la precipitación. Sin embargo, esta relación ofrece sólo una visión parcial, teniendo en cuenta que el volumen de agua almacenado en el azud tiene influencia directa de factores como la pérdida de agua por evaporación, flujo afluente, flujo efluente, además de elementos indirectos que influencian en la variación de estos y que no se consideraron en el estudio. Sin embargo, fue posible identificar que el depósito sobrepasó su capacidad máxima en un total de 16 años, y que estos años fueron clasificados, a partir de la técnica de los cuantiles, como años lluviosos y muy Iluviosos. Estos resultados sugieren que durante la serie en estudio, las oscilaciones en el volumen del depósito pueden ser explicadas también por el clima característico y distribución espacio-temporal de la precipitación de la región.

Palabras Clave: Precipitación; Técnica de los Quantis; Depósito Epitácio Pessoa; volumen; Deficiencia Hídrica.

\section{INTRODUÇÃO}

O suprimento de água doce de boa qualidade é essencial para o desenvolvimento econômico, para a qualidade de vida das populações humanas e para a sustentabilidade dos ciclos no planeta, conforme Alves et al. (2004). O Brasil é considerado um país privilegiado por apresentar $14 \%$ de toda a água doce do mundo, porém a distribuição irregular, associada ao mau uso, faz o país enfrentar sérios problemas de abastecimento de água principalmente em seus centros urbanos. Tal fato alerta para a necessidade de um planejamento e gerenciamento nos recursos hídricos, de forma que os mesmos sejam usados eficientemente (ALBUQUERQUE, 2004).

No que diz respeito às disparidades regionais, o Nordeste é a região que possui maiores restrições hídricas, devido aos longos períodos de estiagens e má distribuição espaço-temporal da precipitação, tornando-a a região de maior necessidade de compreensão da oferta hídrica da bacia e do quanto pode fornecer para o aproveitamento em termos dos múltiplos usos (consuntivos e não- consuntivos) para assim evitar problemas, como por exemplo, situações de escassez local.

A concepção de bacias hidrográficas como unidade de gestão territorial é uma alternativa para harmonia entre as concepções sociais, econômicas e naturais (PORTO; PORTO, 2008). Segundo Galvíncio (2005), diversos processos relacionados ao movimento e qualidade da água são melhores estudados em escala de bacias hidrográficas ou sub-bacias, uma vez que são uma área de 
captação natural de água da precipitação que está baseada na realidade física das formas da terra.

As águas armazenadas no Açude Epitácio Pessoa, localizado na cidade de Boqueirão, no Estado da Paraíba, são captadas pelas sub-bacias hidrográficas do Alto Paraíba e do Rio Taperoá. Essas sub-bacias têm área de aproximadamente 12 mil quilômetros quadrados - que corresponde a cerca $20 \%$ da área do Estado - e estão inseridas na região mais seca do estado, o Cariri Paraibano, parte da região semiárida do Nordeste brasileiro (GALVÍNCIO, 2005). O açude, mais conhecido como Açude de Boqueirão, foi construído pelo Departamento Nacional de Obras Contra as Secas (DNOCS) com recursos financeiros da União. A obra teve início em 1953 e foi inaugurada em 1957 (DNOCS, 2005). Atualmente, o órgão encarregado pela gestão e manutenção deste manancial é a Agência Executiva de Gestão das Águas do Estado da Paraíba (AESA).

A importância do Açude de Boqueirão para a região é que este manancial abastece, na atualidade, 17 municípios e três distritos, dentre eles a cidade de Campina Grande, um dos principais centros urbanos do interior do nordeste brasileiro, informações fornecidas pela Companhia de Água e Esgoto da Paraíba (CAGEPA, 2016). Dessa forma, o açude exerce uma função de intensa relevância na economia local e estadual, sendo a principal fonte de sobrevivência para milhares de pessoas que residem nestas localidades.

Frente à importância do açude para toda a região abastecida pelo mesmo, e principalmente, pelos problemas verificados nos últimos anos, em que devido ao aumento da demanda e o crescimento dos municípios o volume de água armazenada no Açude Epitácio Pessoa não tem sido o bastante para suprir as demandas existentes, principalmente em anos de secas prolongadas como a que ocorreu entre os anos de 2012 a 2017 (AESA, 2019); em 18 de junho de 2016 o reservatório de Boqueirão atingiu o chamado volume morto e, por conta disto a captação de água passou a ser feita por bombas flutuantes, como afirmou o gerente regional da Cagepa, Simão Almeida, ao site do Jornal da Paraíba em dezembro de 2015. Em abril de 2017, chegou ao pior nível volumétrico da história, apresentando apenas $2,9 \%$ da sua capacidade total (AESA, 2019). Atualmente, após a chegada das águas da Transposição do Rio São Francisco e segundo as informações contidas no site da AESA $^{1}$ o mesmo está fora da situação crítica (menor que $5 \%$ do seu volume total) encontrandose na categoria de reservatórios em observação, entretanto, apresenta volume menor que $20 \%$ de sua capacidade total (17,97\%, informação do site no dia 0411-2019).

Sabendo que a precipitação é considerada uma das variáveis hidrológicas mais importantes, pois a estimativa da precipitação em uma bacia explana uma noção da disponibilidade hídrica da região (PAZ, 2004), e tendo em vista que na área de estudo, as duas sub-bacias localizam-se na região semiárida, e este elemento apresenta grande variação temporal e espacial, o entendimento melhor da variabilidade, anomalias e o consequente impacto no volume do açude é de grande valia para a tomada de decisão por parte dos gestores deste manancial.

Tendo em visto a crise hídrica observada nos últimos anos e as consequências geradas para os municípios abastecidos pelo açude Epitácio

\footnotetext{
${ }^{1}$ http://www.aesa.pb.gov.br/aesa-website/monitoramento/ultimos-volumes/
} 
Pessoa, surge a importância de estudos no tocante à temática para tentar adquirir informações que auxiliem no entendimento da evolução espaçotemporal da precipitação relacionado ao quantitativo armazenado no manancial.

Dessa forma, o objetivo deste trabalho é analisar a relação entre a variabilidade (distribuição) espaço-temporal da precipitação nas sub-bacias - Rio Taperoá e Alto Curso do Rio Paraíba - que abastece o Açude Epitácio Pessoa com o volume armazenado, com o intuito de compreender a relação entre esses elementos e, assim, buscar informações qualitativas e quantitativas para uma melhor gestão dos recursos hídricos na região.

\section{MATERIAIS E MÉTODOS}

\section{1 ÁREA DE ESTUDO}

A área de estudo compõe as sub-bacias hidrográficas do Alto Curso do Rio Paraíba e do Rio Taperoá, localizadas entre as coordenadas $06^{\circ} 51^{\prime} 47^{\prime \prime}$ e $08^{\circ} 18^{\prime} 11^{\prime \prime}$ de latitudes sul e entre $36^{\circ} 00^{\prime} 10^{\prime \prime}$ e $37^{\circ} 21^{\prime} 23^{\prime \prime}$ de longitude oeste e possui os índices pluviométricos mais baixos de todo o Estado da Paraíba, pois pertencem ao território conhecido como Cariri paraibano onde as condições semiáridas do clima e a geologia do solo cristalino dificultam a infiltração e o acúmulo de água no solo (LUCENA; PACHECO, 2008).

Na Figura 1, pode-se visualizar a localização e a distribuição espacial dos municípios inseridos em cada uma das sub-bacias. Na sub-bacia do Alto Curso do Rio Paraíba estão inseridos de forma total ou parcial a área de 18 municípios e na do Rio Taperoá, 23 municípios. Na mesma figura, pode-se observar também a rede de drenagem do Açude Epitácio Pessoa, abastecida pelos municípios presentes nas sub-bacias.

O açude está localizado entre as coordenadas $07^{\circ} 28^{\prime} 04^{\prime \prime}$ e $07^{\circ} 33^{\prime} 32^{\prime \prime}$ de latitudes sul e entre $36^{\circ} 08^{\prime} 23^{\prime \prime}$ e $36^{\circ} 16^{\prime} 51^{\prime \prime}$ de longitude oeste, a $420 \mathrm{~m}$ de altitude (ARAÚJO, 2010). Teve sua capacidade inicial de acumulação de água estimada em 535.680.000 $\mathrm{m}^{3}$ (DNOCS, 2005). Atualmente, após o levantamento batimétrico realizado pela Secretaria Extraordinária do Meio Ambiente, dos Recursos Hídricos e Minerais (SEMARH) no ano de 2004, a capacidade máxima do reservatório é de $411.686 .287 \mathrm{~m}^{3}$ que representa uma perda de 124 milhões de metros cúbicos de água, cerca de 23,14\% de seu volume inicial. De acordo com BRITO (2008), a batimetria realizada indicou, através da quantificação do volume de sedimentos no açude, que essa perda se deu devido ao assoreamento de sua bacia hidráulica. 


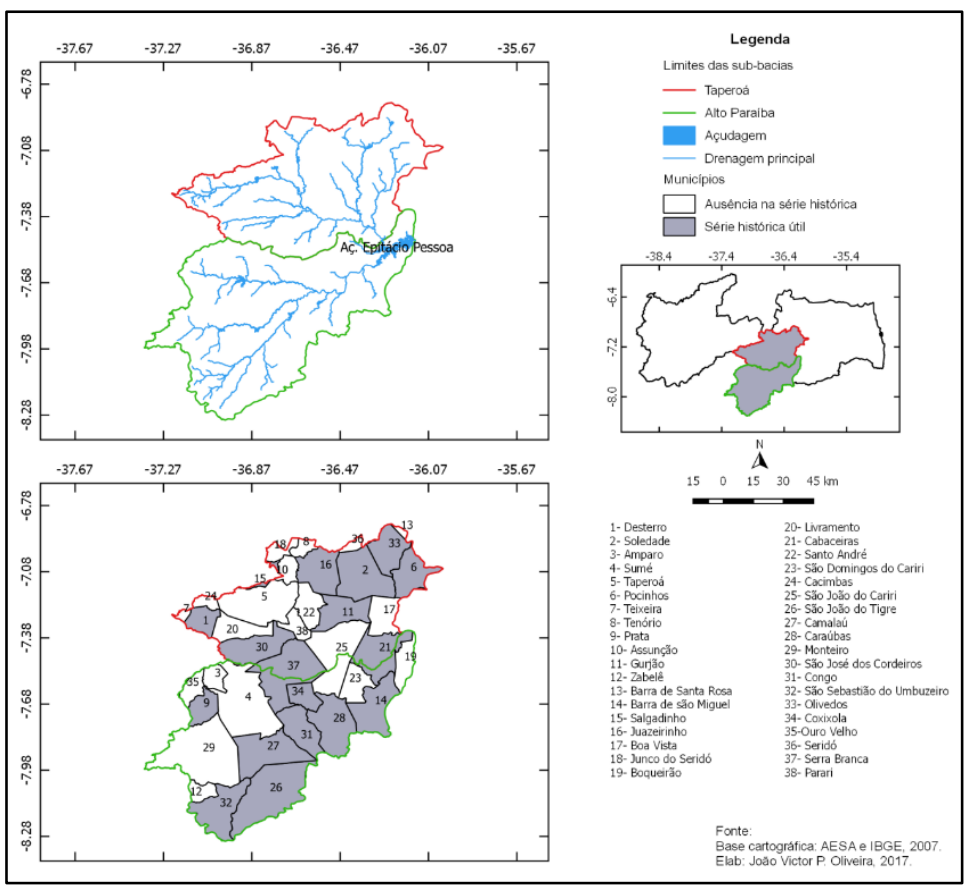

Figura 1 - Mapa de drenagem e localização do Açude Epitácio Pessoa e dos municípios que compõem as sub-bacias do Alto Curso do Rio Paraíba e do Rio Taperoá que drenam água para o Açude Epitácio Pessoa.

Segundo a Agência Nacional das Águas (ANA), o volume alerta do açude equivale a aproximadamente $24 \%$ de sua capacidade máxima atual, cerca de $100.000 .000 \mathrm{~m}^{3}$ e, de acordo com o atual diretor de expansão da CAGEPA, através de uma entrevista dada ao Jornal da Paraíba em 2015, o volume morto - cota limite que inviabiliza o bombeamento para o abastecimento público - do reservatório corresponde a aproximadamente $13 \%$ do volume total, cerca de $52.613 .507 \mathrm{~m}^{3}$.

\subsection{DADOS}

Os dados de volume de água do Açude Epitácio Pessoa foram fornecidos pela Agência Executiva de Gestão das Águas do Estado da Paraíba (AESA) para o período de 1972 a 2016, resultando em um total de 45 anos, com inexistência de informações para o ano de 1977.

Também foram utilizados dados de precipitação mensal para 17 municípios localizados nas sub-bacias do Alto Curso do Rio Paraíba e do Rio Taperoá, ressaltados na Figura 1 na cor cinza, provenientes da AESA (Agência Executiva de Gestão das Águas do Estado da Paraíba) e do DCA (Departamento de Ciências Atmosféricas) para o período de 1972 a 2016 . No entanto, o período referente aos anos de 1991 a 1993 também possui inexistência de dados, resultando em um total de 42 anos de estudo. 


\subsection{METODOLOGIA}

A princípio, foram levantados os dados de precipitação para organização dos mesmos e realização da análise de consistência a fim de escolher as estações e o período de estudo. Foram descartados os postos com grandes falhas ou séries muito curtas de dados. Após a análise de consistência e definição do período a ser estudado e dos postos pluviométricos a serem trabalhados, foram elaborados gráficos diários, mensais e anuais para o estudo da variabilidade tanto da precipitação quanto do volume de água armazenado no açude. Ressalta-se que esta análise também foi realizada separadamente para cada sub-bacia - Rio Taperoá e Alto curso do Rio Paraíba. Para tanto se utilizou a planilha eletrônica Excel da Microsoft.

Esses passos iniciais visaram definir e caracterizar o comportamento geral das precipitações em escala temporal e espacial, como também avaliar a variação da mesma durante o período trabalhado em toda a extensão das subbacias que drenam água para o Açude Epitácio Pessoa, bem como a caracterização da série temporal do volume no açude.

Para a seleção de eventos extremos, a técnica utilizada foi a dos Quantis (Q), proposta por Pinkayan (1966) e, bastante difundidas por Xavier et al. (2002). Esta técnica possibilita estabelecer ou delimitar faixas com regimes de chuvas diferenciados, tais como: extremamente seco (ES), muito seco (MS), seco (S), normal (N), chuvoso (C), muito chuvoso (MC) e extremamente chuvoso (EC) além de ser uma técnica imune a qualquer assimetria na função densidade de probabilidade. Para um melhor entendimento da utilização da técnica estatística e a noção de quantis, supõe-se que a chuva em um determinado local, acumulada em certo intervalo (mês, bimestre, trimestre, quadrimestre, semestre, ou até mesmo o ano inteiro etc.), com respeito a anos consecutivos, possa ser representada em termos por uma variável aleatória contínua. Xavier et al. (2002) cita os quantis extremos, útil para analisar a ocorrência e frequência de extremos climáticos, com ordens quantílicas de $5 \%$ e 95\% referentes aos extremos de seca e chuva, respectivamente.

Para a realização deste estudo, os quantis utilizados referem-se às probabilidades de 0,$15 ; 0,35 ; 0,65 ; 0,85$. Dessa forma, serão determinados e classificados limites de intensidade para a chuva anual nas sub-bacias em estudo, relacionada às ordens quantílicas descritas na Tabela 1. Foi aplicada a técnica para os 19 municípios das sub-bacias do Alto Curso do Rio Paraíba e Rio Taperoá, para o período de 1972 a 2016.

Tabela 1 - Classificação das categorias e probabilidades da precipitação anual relacionada às ordens quantílicas para as sub-bacias do Rio Taperoá e Alto Curso do Rio Paraíba.

\begin{tabular}{cc}
\hline CATEGORIAS & PROBABILIDADE \\
\hline Muito Seco (MS) & $\mathrm{P} \leq \mathrm{Q}_{0,15}$ \\
Seco (S) & $\mathrm{Q}_{0,15}<\mathrm{P} \leq \mathrm{Q}_{0,35}$ \\
Normal (N) & $\mathrm{Q}_{0,35}<\mathrm{P} \leq \mathrm{Q}_{0,65}$ \\
Chuvoso (C) & $\mathrm{Q}_{0,65}<\mathrm{P} \leq \mathrm{Q}_{0,85}$ \\
Muito Chuvoso (MC) & $\mathrm{P}>\mathrm{Q}_{0,85}$ \\
\hline
\end{tabular}


necessário:

Para calcular os quantis de qualquer série de dados de chuvas é

1- Dispor das observações $x_{1}, x_{2}, \ldots, x_{n}$ ( $N$ é o número de observações, no caso deste trabalho anos);

2- Ordenar os dados: $\mathrm{y}_{1}<\mathrm{y}_{2}<\ldots \ldots<\mathrm{y}_{\mathrm{j}}<\ldots . . \mathrm{y}_{\mathrm{N}}$;

3- Evidenciar qual o número de ordem $\mathrm{j}$ de cada elemento $\mathrm{y}_{\mathrm{j}}$ da série assim ordenada;

4- Para cada elemento $y_{j}$ determinar a ordem quantílica $p_{j}$ que Ihe corresponde,

$$
p_{j}=\frac{j}{(N+1)}
$$

5- Finalmente, para calcular o quantil $Q_{p}$ para uma ordem quantílica p qualquer, segue-se:

a- Se $\mathrm{p}$ coincidir com algum $\mathrm{p}_{\mathrm{j}}$ já obtido através de (1) tem-se,

$$
Q_{p}=Q_{p j}=y_{j}
$$

b- Se $\mathrm{p}$ não coincidir, haverá um índice $\mathrm{j}$ tal que $\mathrm{p}_{\mathrm{j}}<\mathrm{p}<\mathrm{p}_{\mathrm{j}+1}$, donde, $\mathrm{Q}_{\mathrm{p}}$ será obtido por interpolação como segue:

$$
Q_{p}=y_{j}+\left\{\frac{\left[p-p_{j}\right]}{\left[p_{j+1}-p_{j}\right]}\right\} *\left[y_{j+1}-y_{j}\right]
$$

Os casos a e b podem ser englobados na mesma equação (3), supondo $p_{j} \leq p<p_{j+1}$; obviamente, quando $p=p_{j}$ a equação (3) reduz-se a $Q_{p}=y_{j}$. Logo, (3) é a equação geral para os cálculos dos quantis.

\section{RESULTADOS E DISCUSSÃO}

\subsection{VARIABILIDADE DA PRECIPITAÇÃO NAS SUB-BACIAS DO ALTO CURSO DO RIO PARAÍBA E DO RIO TAPEROÁ}

Iniciaram-se as análises, observando o comportamento mensal dos dados de precipitação, baseados nos postos pluviométricos inseridos nos 17 municípios localizados nas sub-bacias do Alto Curso do Rio Paraíba e do Rio Taperoá. Lembrando que, de acordo com a literatura, a disponibilidade hídrica proveniente da precipitação é um fator determinante para quantificar a necessidade de abastecimento de água de uma população, conforme Santos et al. (2014), além de ser o principal input de recarga de um açude.

A variabilidade mensal da precipitação nas sub-bacias, para os 42 anos em análise, apresenta o seu período mais úmido entre os seis primeiros meses do ano (janeiro a junho), como mostra a Figura 2, sendo o mês de março o que apresenta os maiores volumes pluviométricos (acima de $100 \mathrm{~mm}$ em média); e o trimestre mais seco compreende de setembro a novembro, com precipitações 
que não ultrapassam $6 \mathrm{~mm}$. Os mesmos períodos também são apontados nos estudos de Araújo (2010) e Brito (2008). É válido salientar também que, o período chuvoso (janeiro a junho) da região contribui, aproximadamente, com $84 \%$ da precipitação média esperada no ano que é de $481,32 \mathrm{~mm}$, tornando-se o período mais propício à drenagem de água para o armazenamento de água nos mananciais, principalmente ao reservatório do açude Epitácio Pessoa.

Em resumo pode-se atestar, analisando a Figura 2, a grande variabilidade mensal da precipitação, em que são verificados claramente dois períodos bem contrastantes, um seco e um chuvoso, bem definidos, refletindo uma característica marcante da região semiárida paraibana.

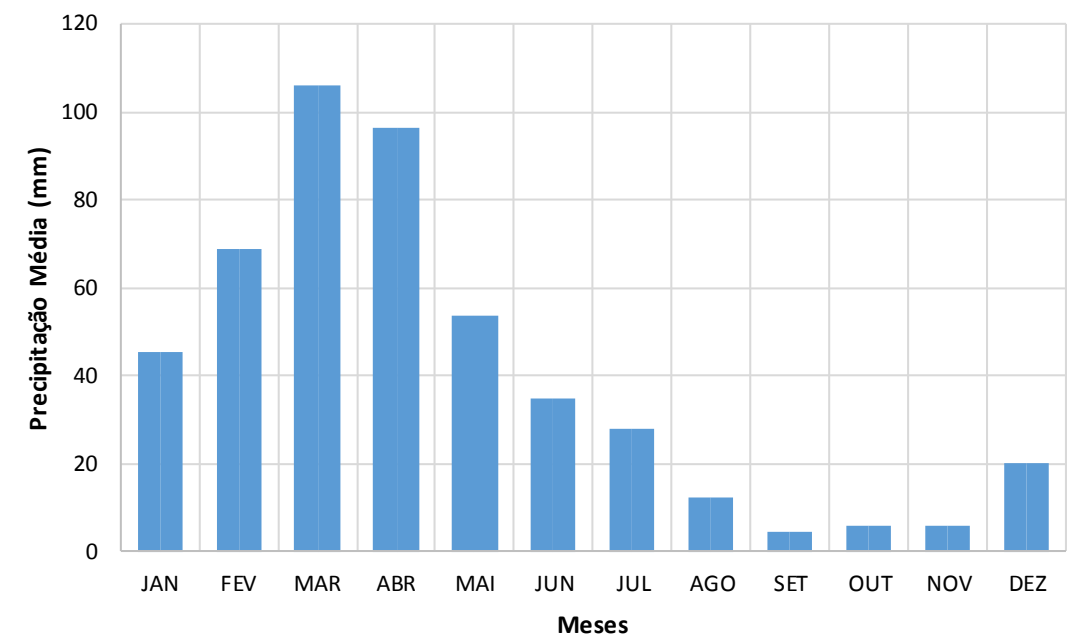

Figura 2 - Variabilidade mensal da precipitação para as sub-bacias do Rio Taperoá e Alto Curso do Rio Paraíba (1972-2016).

A alta variabilidade interanual da precipitação é analisada na Figura 3, como é esperado quando se trata do elemento precipitação, principalmente na região em estudo. Tendo em vista essa variabilidade, destacam-se os anos de 1974, 1985, 2004, 2007, 2009 e 2011, que podem ser considerados anos chuvosos por apresentarem um acumulado maior que $684 \mathrm{~mm}$, que corresponde a cerca de $42 \%$ acima da média anual da precipitação para a região, enquanto os anos de 1982, 1983, 1990, 1998, 2012 e 2016 são anos que apresentam valores de precipitação bem abaixo da média e foram anos marcados, historicamente, pela seca como relatados e identificados no estudo de Ferreira e Mello (2005), Marengo et al. (2016). Ressalta-se que, de acordo com o banco de dados da AESA, há inexistência de dados para os anos 1991, 1992 e 1993, como indicado na Figura 3. 


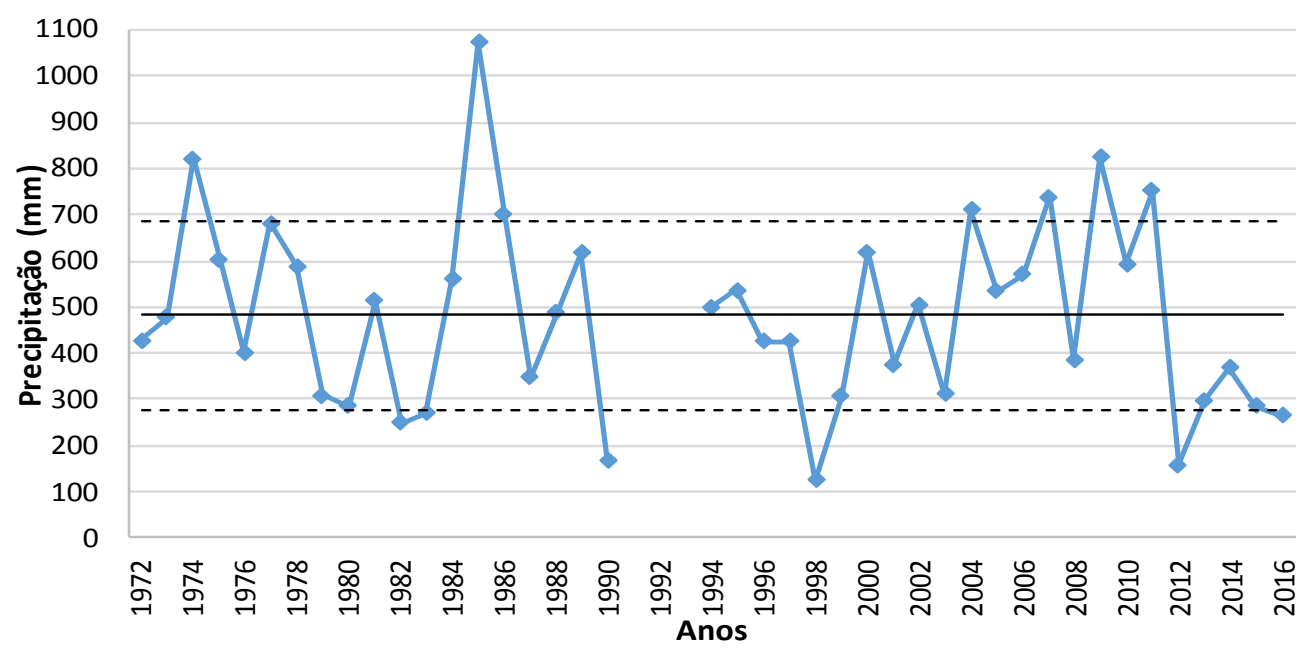

Figura 3 - Variação interanual da precipitação para as sub-bacias do Rio Taperoá e Alto Curso do Rio Paraíba no período 1972 a $2016\left({ }^{-}(x)=481,32 \mathrm{~mm}\right.$ e $\left.\delta=203,65 \mathrm{~mm}\right)$.

\subsection{IDENTIFICAÇÃO DE EVENTOS EXTREMOS DE PRECIPITAÇÃO}

Diante do comportamento interanual da precipitação e para o período chuvoso na região em estudo foi aplicada a técnica dos quantis, pois como os dados de precipitação não seguem uma distribuição normal, essa técnica tornase o melhor método para classificar a precipitação quanto a sua intensidade (SENA, 2017). Dessa forma, a técnica consiste em categorizar os anos em Muito Seco (MS), Seco (S), Normal (N), Chuvoso (C) e Muito Chuvoso (MC), como foi explicado anteriormente, aplicando-a em intervalos de 0,$15 ; 0,35 ; 0,65$ e 0,85 que representam as probabilidades ou frequências esperadas para cada um dos eventos que podem vir a ocorrer na sequência ou série temporal. Verifica-se, na Tabela 2, a classificação da intensidade da precipitação anual e para o período chuvoso, referentes às ordens quantílicas obtidas para a região das sub- bacias do Alto Curso do Rio Paraíba e Rio Taperoá.

Tabela 2 - Classificação da intensidade da precipitação anual para as sub-bacias do Rio Taperoá e Alto Curso do Rio Paraíba relacionadas às ordens quantílicas.

\begin{tabular}{|c|c|c|}
\hline \multirow[t]{2}{*}{ CATEGORIAS } & \multicolumn{2}{|c|}{ INTENSIDADE DA PRECIPITAÇÃO (mm) } \\
\hline & ANUAL (PA) & PERÍODO CHUVOSO (PC) \\
\hline Muito Seco (MS) & $\mathrm{PA} \leq 276,5$ & $P C \leq 204,7$ \\
\hline Seco (S) & $276,5<\mathrm{PA} \leq 376,1$ & $204,7<P C \leq 300$ \\
\hline Normal (N) & $376,1<P A \leq 560,2$ & $300<\mathrm{PC} \leq 456,1$ \\
\hline Chuvoso (C) & $560,2<\mathrm{PA} \leq 707,2$ & $456,1<P C \leq 623,9$ \\
\hline Muito Chuvoso (MC) & $P A>707,2$ & $P C>623,9$ \\
\hline
\end{tabular}

Classificando a precipitação anual e a precipitação do período chuvoso para cada ano em estudo de acordo com as ordens quantílicas, percebe-se com base na Figura 4 que apesar de ter um maior percentual na categoria abaixo dos valores normais, ou seja, categoria seca e muito seca, representando um total 
de $36 \%$, esse valor é muito próximo da frequência observada nos anos classificados com chuvas acima da média (33\%), indicando que, apesar da região apresentar períodos com secas drásticas, também tem períodos com precipitações "abundantes" (termo esse relativo ao volume pluviométrico para a região), indicando desta forma que, são necessários conhecimento acerca da variabilidade e de mecanismos que visem adaptação e mitigação nos períodos mais drásticos. Ressaltando que os anos considerados na categoria normal apresentam frequência relativa bem próxima a estes eventos extremos (categorias secas e chuvosas).

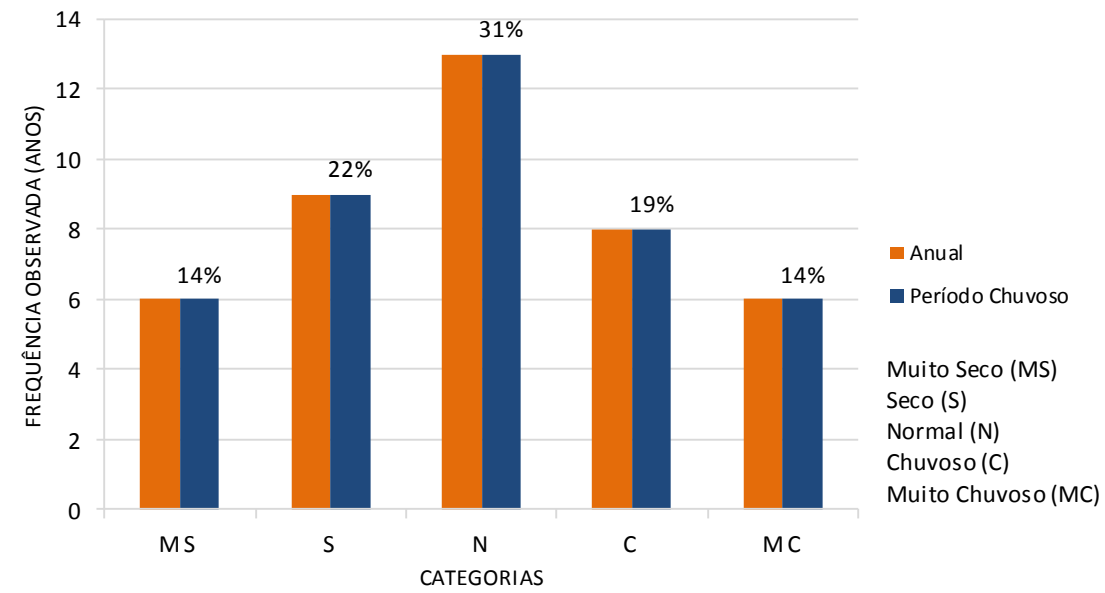

Figura 4 - Frequência relativa das categorias de intensidade da precipitação para os períodos anual e chuvoso das sub-bacias do Alto Curso do Rio Paraíba e Rio Taperoá (1972-2016)

Apesar dos dois períodos apresentarem frequências aproximadas, em termos de quantidade de anos secos, normais e chuvosos para a série em estudo, é possível perceber através da Tabela 3, que a classificação de um ano no PA (período anual) não necessariamente corresponde a mesma classificação no PC (período chuvoso - relembrando que o período chuvoso em questão são os meses de janeiro a junho). Podem-se citar como exemplos os anos de 1975, 1989, 2000 e 2010, classificados no PA como anos chuvosos e no PC como anos normais, indicando que os meses do período seco contribuíram para o ano ser classificado como um ano de precipitações acima da média esperada para as sub-bacias. Em contrapartida, os anos de 1981, 1984, 1995 e 2002, foram considerados normais no PA, contudo os períodos chuvosos apresentaram-se com chuvas acima do esperado, ou seja, PC com volumes pluviométricos maiores.

Contudo, é visível perceber também na Tabela 3 que, na maioria dos anos, existe uma relação, como esperado, entre a classificação do período chuvoso e a anual, principalmente porque o período chuvoso da região apresenta a maior contribuição da precipitação anual, isto foi observado em $76 \%$ dos anos em análise. É perceptível também que a técnica conseguiu captar os anos extremos, anos de secas intensas na região, como 1982/83, 1990, 1998, 2012 e 2016 e anos de intensas chuvas, 1974, 1985, 2004, 2008/09 e 2011 (MARENGO et al., 2016). 
Tabela 3 - Classificação da precipitação anual (PA) e do período chuvoso (PC) para as sub-bacias do Alto curso do Rio Paraíba e do rio Taperóa (1972-2016) de acordo com a técnica dos Quantis.

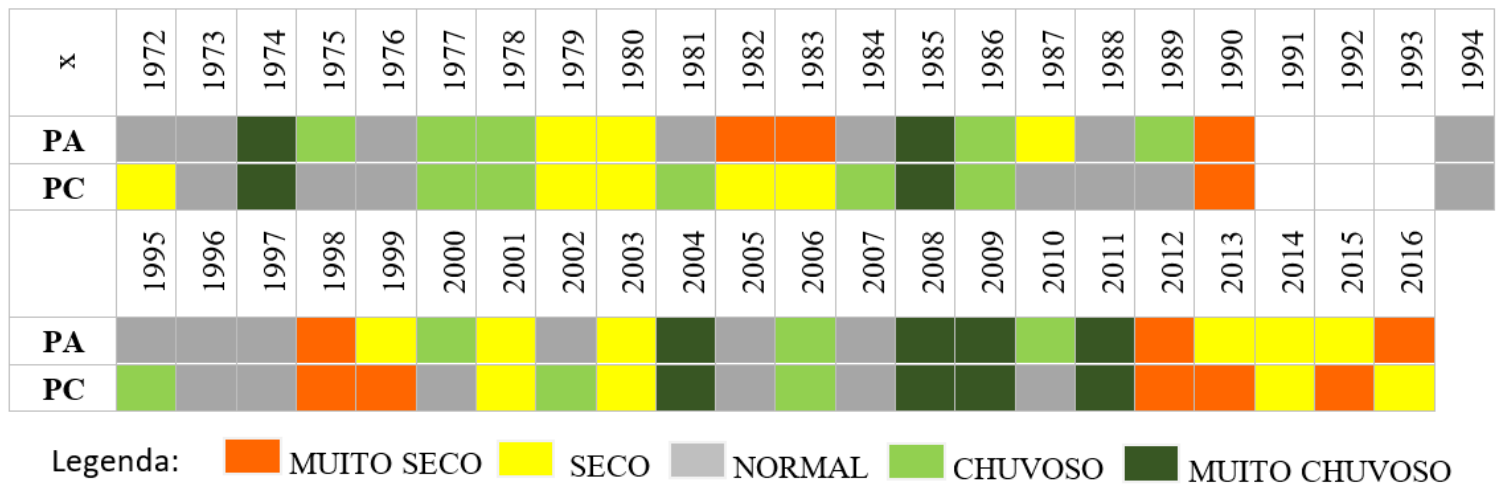

\subsection{ANÁlise dO VOLUME dE ÁGUA NO AÇUDE EPITÁCIO PESSOA}

Observando as Figuras 5, 6 e 7 (barras na cor cinza) verifica-se que o volume do açude Epitácio Pessoa apresenta os maiores valores sempre nos primeiros meses do ano, vindo a decrescer nos últimos meses. Os anos em que o reservatório apresentou volumes maiores e quando o mesmo teve sua capacidade hídrica reduzida são facilmente visualizados nas figuras citadas anteriormente, sendo assim, verifica-se que o açude atingiu sua capacidade máxima em um total de 16 anos, conforme a Tabela 4. Estes resultados coincidem com os estudos de Silva et al. [2015] e Araújo (2010).

Tabela 4 - Anos em que o Açude Epitácio Pessoa atingiu a capacidade máxima.

\begin{tabular}{cc}
\hline ANOS DE SANGRIA DO AÇUDE EPITÁCIO PESSOA \\
\hline 14 de Abril de 1973 & 03 de Março de 1986 \\
01 de Março de 1974 & 09 de Abril de 1989 \\
07 de Março de 1975 & 02 de Fevereiro de 2004 \\
30 de Março de 1976 & 28 de Março de 2005 \\
03 de Março de 1978 & 15 de Maio de 2006 \\
19 de Março de 1981 & 22 de Março de 2008 \\
10 de Abril de 1984 & 04 de Maio de 2009 \\
14 de Fevereiro de 1985 & 06 de Março de 2011 \\
\hline
\end{tabular}




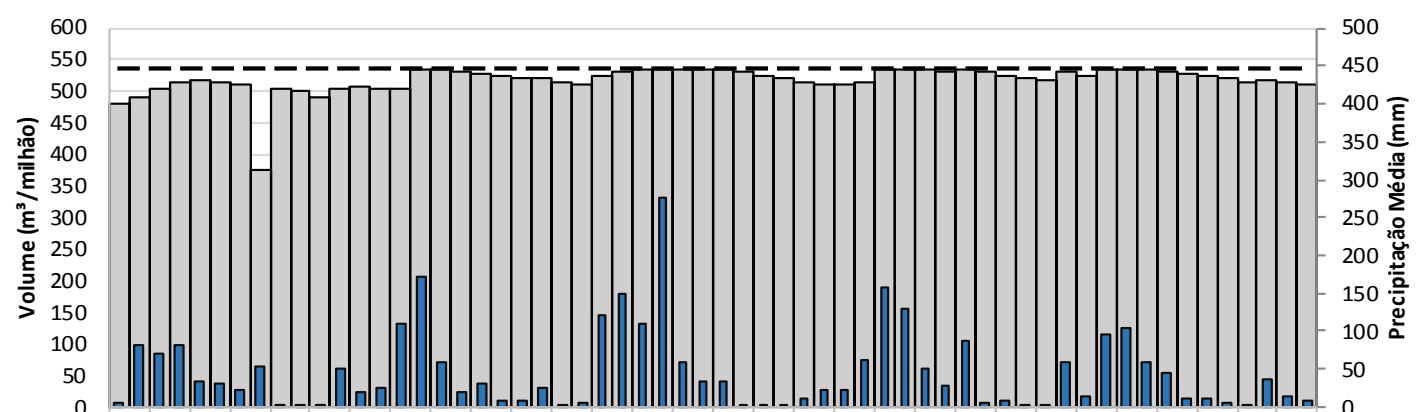

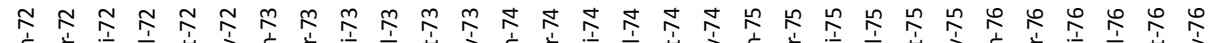

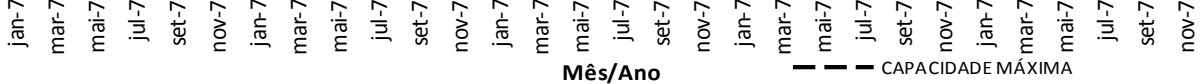

\section{( B )}

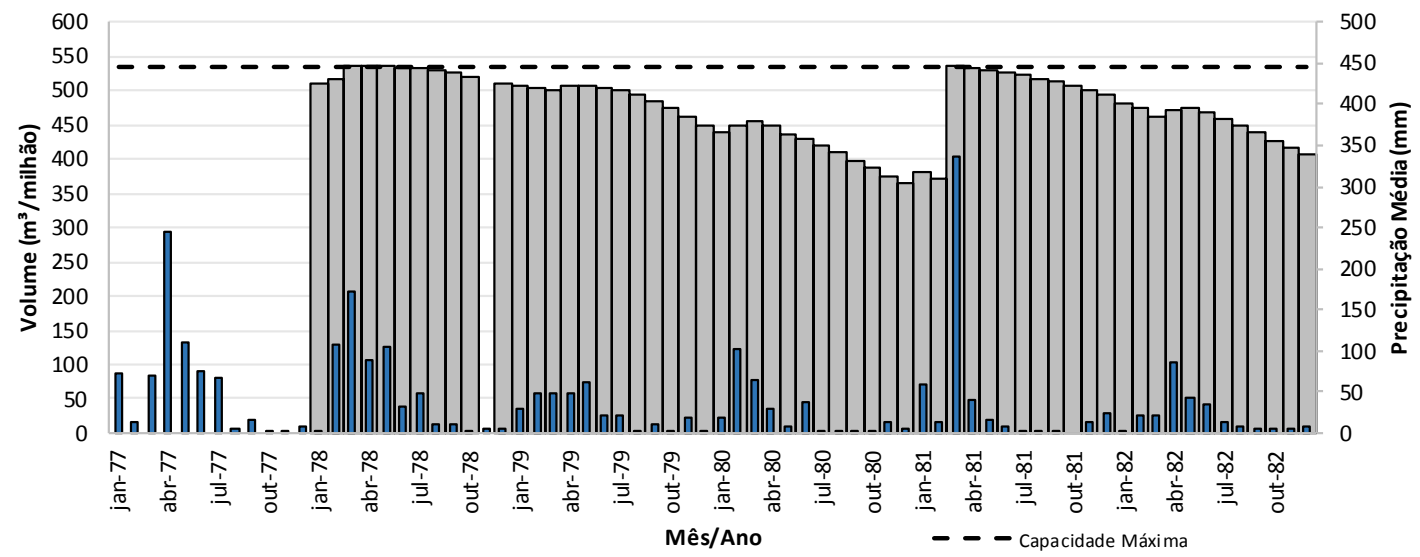

( C )

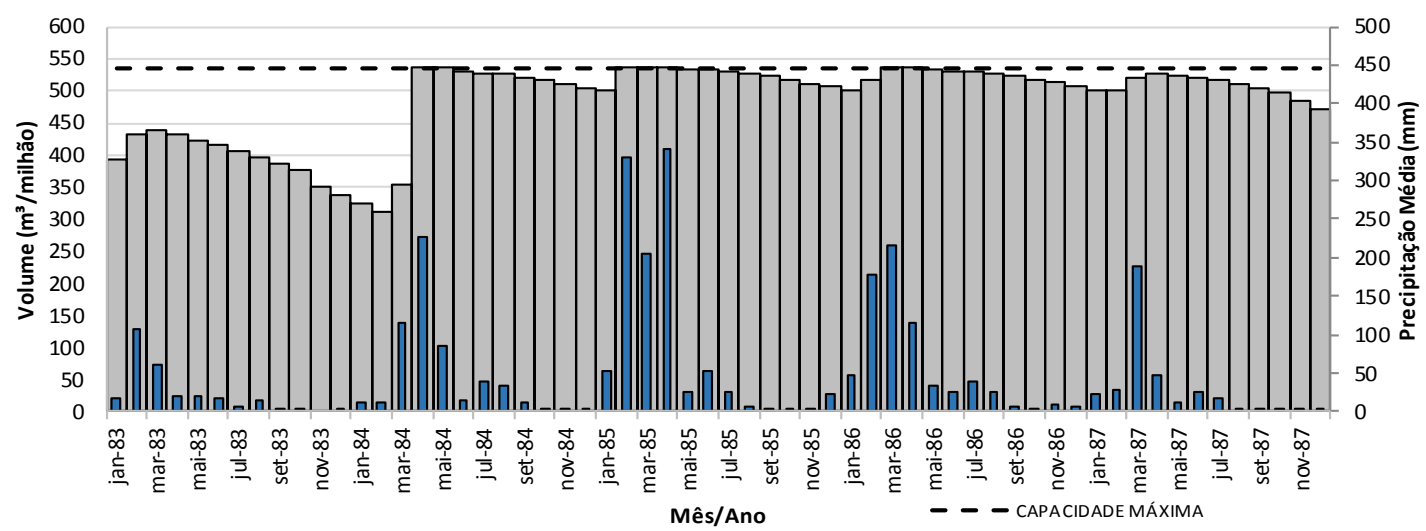

Figura 5 - Variação mensal do volume (cinza) e precipitação (azul) para o Açude Epitácio Pessoa no período de: (A) 1972 - 1976; (B) 1977 - 1982; (C) 1983 - 1987. 
(A)

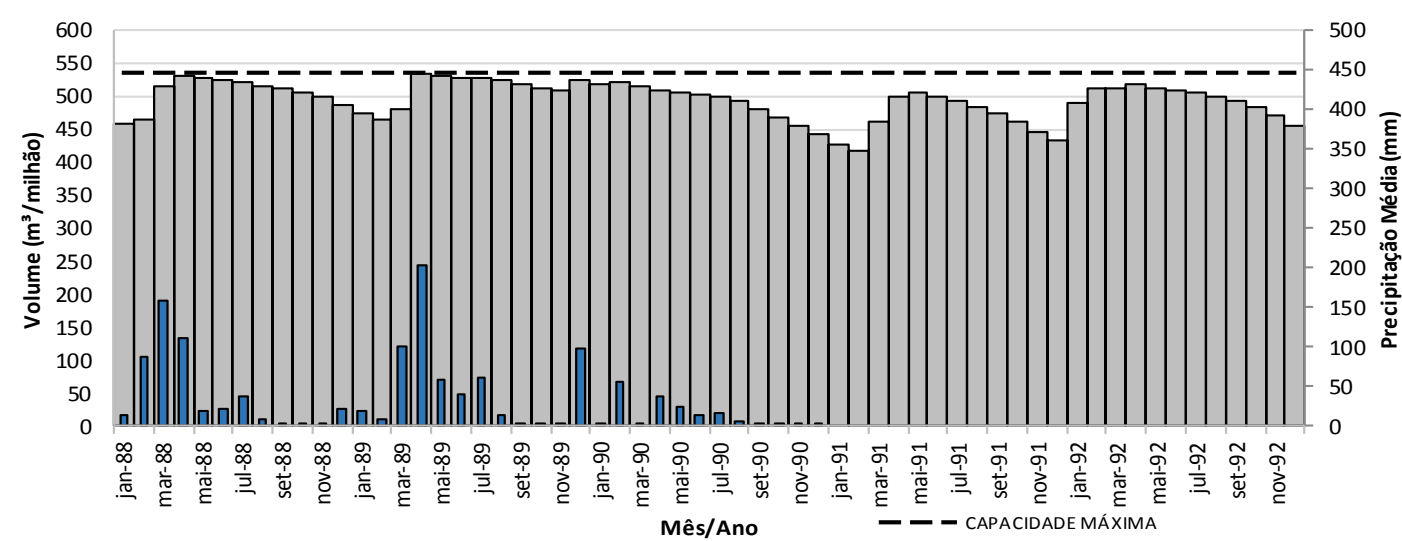

(B)

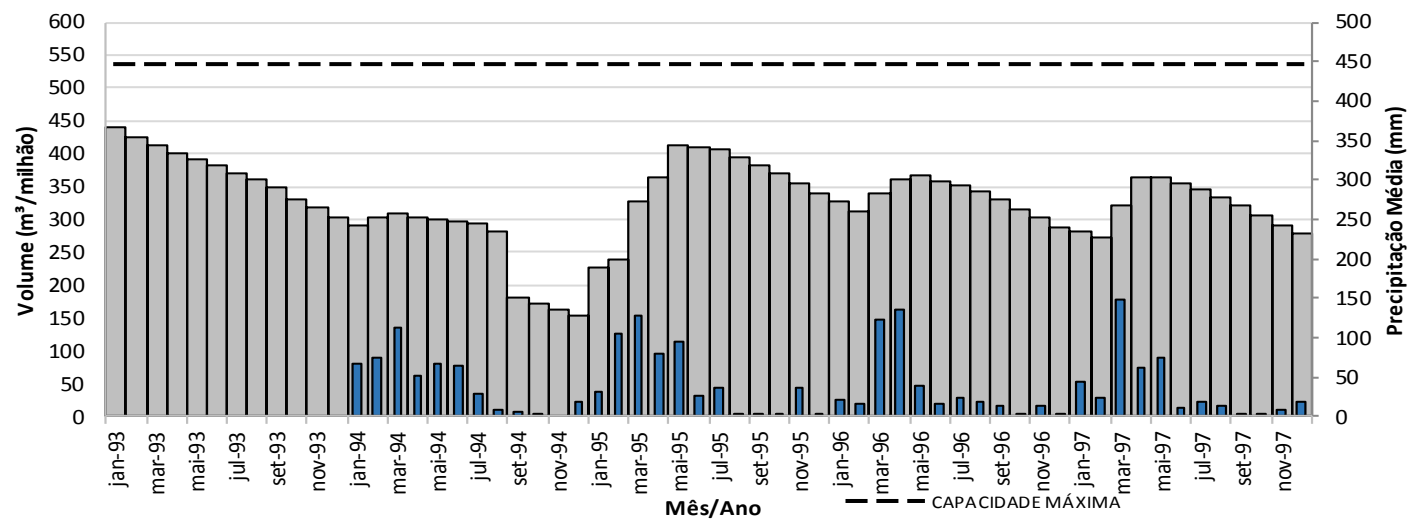

(C)

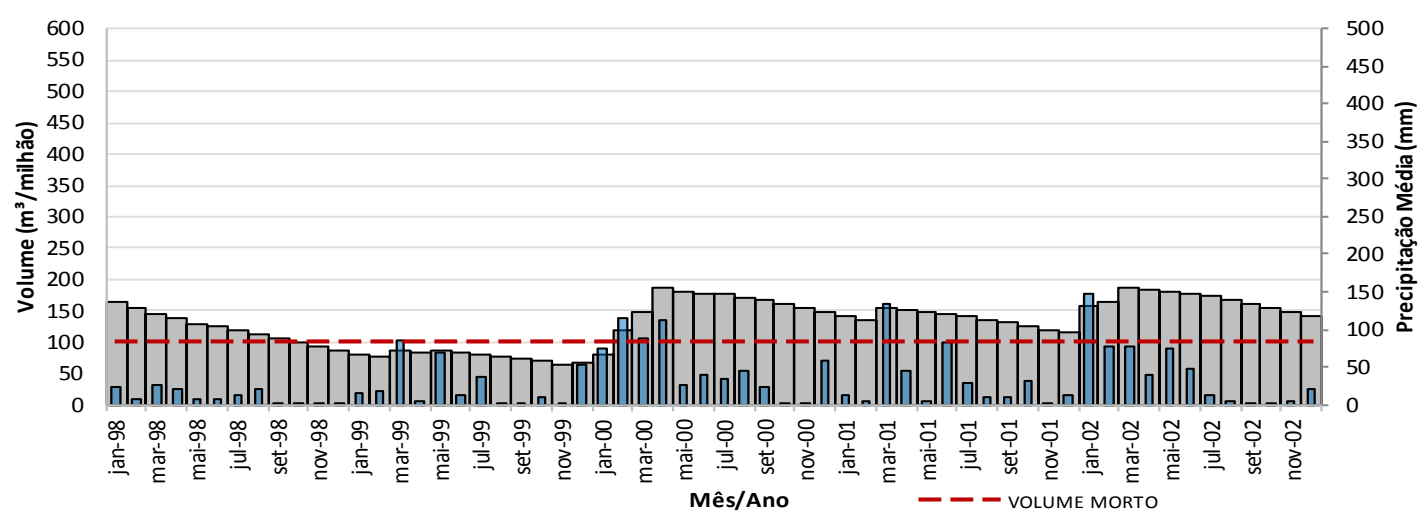

Figura 6 - Variação mensal do volume e precipitação para o Açude Epitácio Pessoa no período de: (A) 1988 - 1992; (B) 1993 - 1997; (C) 1998 - 2002. 
( A )

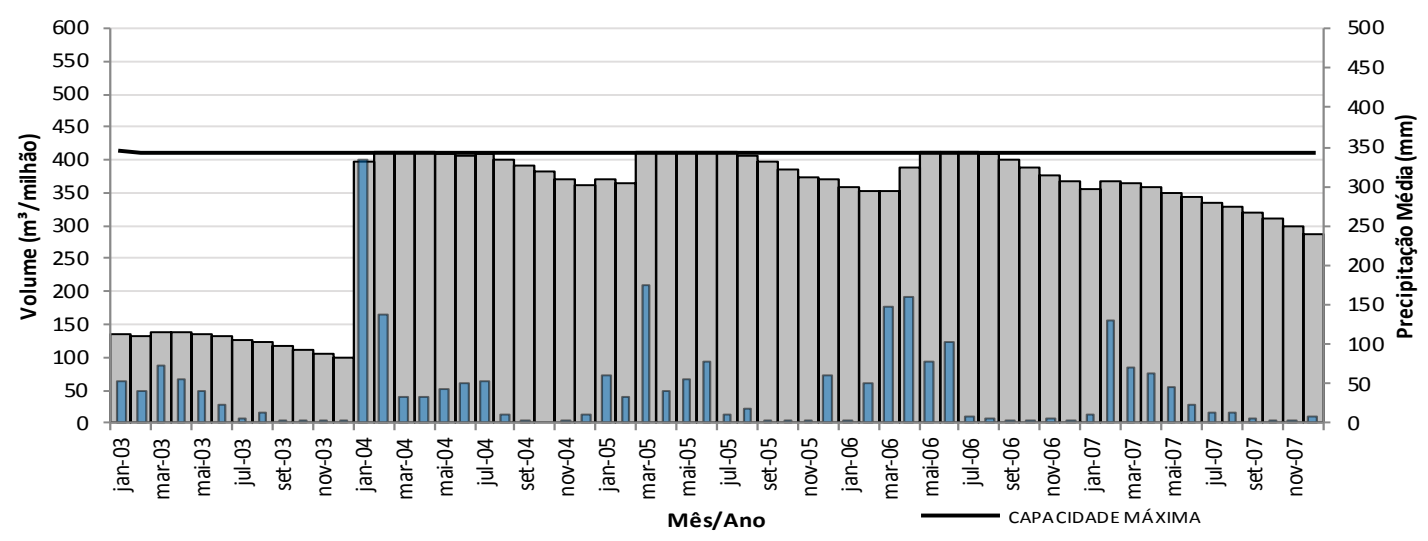

\section{( B )}

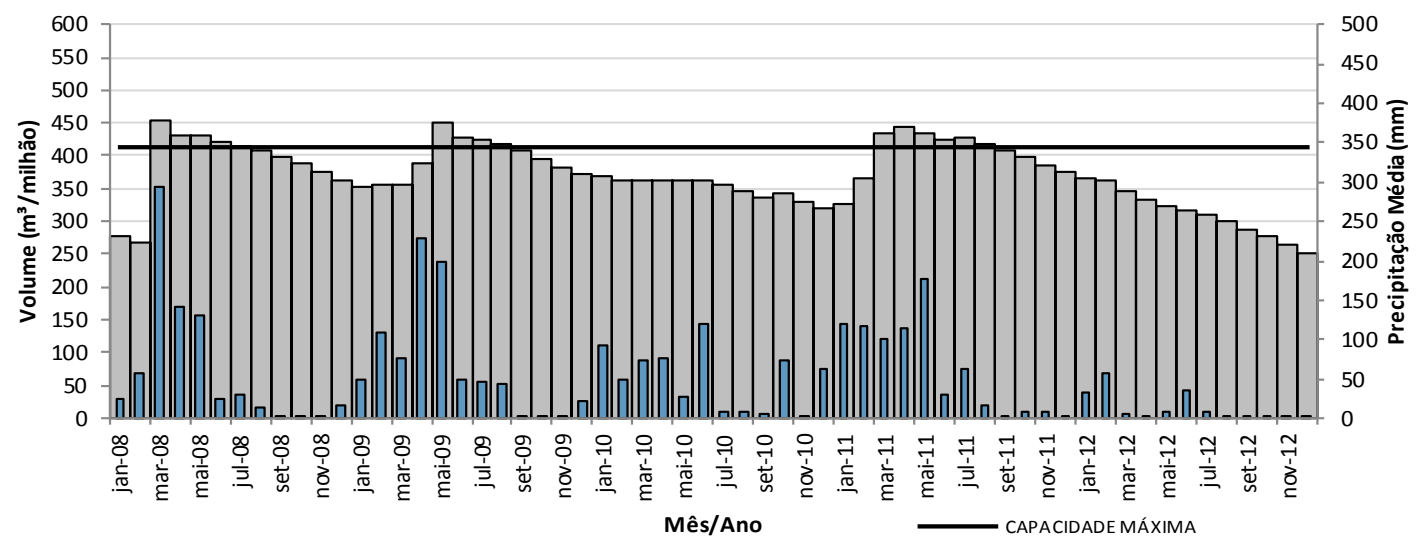

( C )

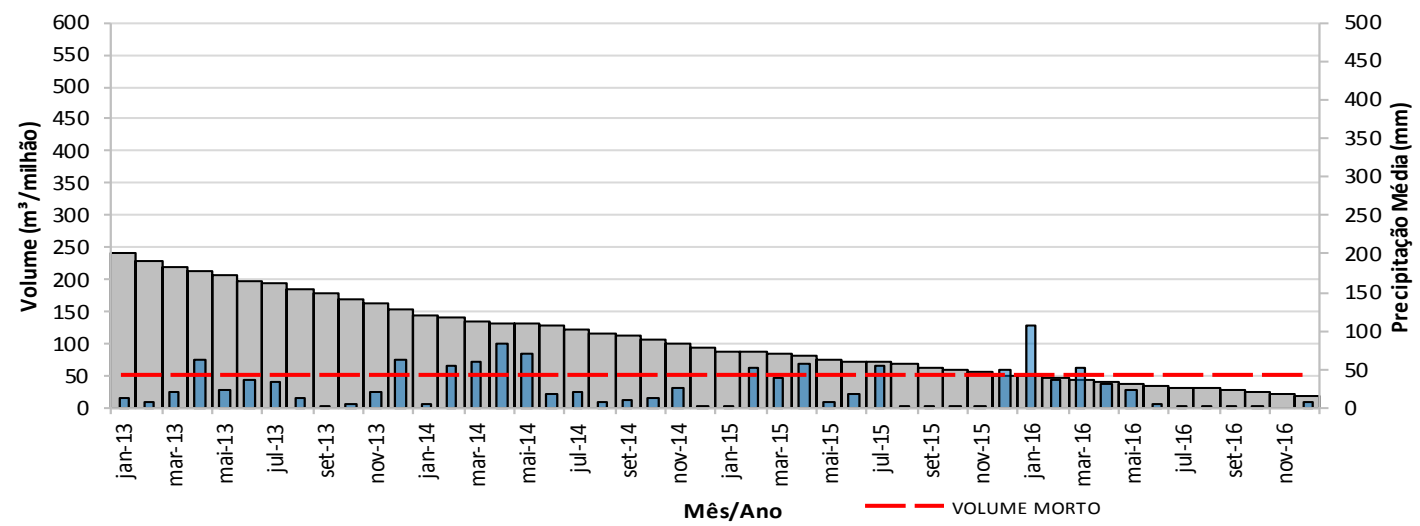

Figura 7 - Variação mensal do volume e precipitação para o Açude Epitácio Pessoa no período de: (A) 2003 - 2007; (B) 2008 - 2012; (C) 2013 - 2016. 
Ao analisar o comportamento mensal do volume armazenado no açude ano a ano, percebe-se que entre os anos entre 1972 a 1992, apesar da variabilidade inerente ao volume, em termos de percentual o açude apresentouse, geralmente, com capacidade acima dos $84 \%$, apresentando volumes superiores a 450 milhões de metros cúbicos. Durante os 21 anos mencionados, apenas nos anos de 1980 e 1983 houve um decaimento no volume do manancial, chegando a atingir $58 \%$ de sua capacidade, tal fato é explicado pelas secas sucessivas ocorridas em 1979-1980 e 1982-1983 (MARENGO et al., 2016), anos classificados nas categorias seco e muito seco (vide Tabela 3), respectivamente, de acordo com o resultado da aplicação da técnica dos quantis.

Diferentemente, após 1992 até o ano de 2003 pode-se considerar um período crítico no que diz respeito ao aporte hídrico, pois é visualizado um decréscimo contínuo no volume do açude chegando a apresentar, como no ano de 1999 (Figura 6-C), valores abaixo da cota de alerta do reservatório $\left(100.000 .000 \mathrm{~m}^{3}\right)$, que culmina com a grande seca ocorrida neste ano, como identificado no estudo de Sena (2017).

Os anos compreendidos entre 2004 e 2011, como pode ser percebido na Figura 7-A, período relativamente extenso ( 7 anos), a região não sofreu com escassez de chuva, refletindo diretamente no aumento do volume do açude Epitácio Pessoa (lembrando que a capacidade neste período é de 411.686 .000 $\mathrm{m}^{3}$ ), que chega a sangrar por 6 anos durante este período, com exceção apenas dos anos de 2007 e 2010. Lembrando que, o ano de 2004 ficou marcado por fortes chuvas no mês de janeiro, sendo considerado o janeiro mais chuvoso de todas as séries de observações até aquele momento, no nordeste do Brasil. As chuvas foram tão intensas que inundaram várias cidades e áreas rurais com o rompimento de barragens e elevação da cota máxima de diversos reservatórios da região (ALVES, 2004).

Em contrapartida, após a sangria do reservatório no ano de 2011, no ano de 2012 a seca voltou a castigar o açude com o retorno do ciclo de anos secos. Com precipitações abaixo da média nas sub-bacias do Alto Paraíba e Taperoá durante esses anos, o volume passou a reduzir dia após dia. Em dezembro de 2016 chegou a 5\% de sua capacidade (AESA, 2017), atingindo o volume morto (52.613.507 $\mathrm{m}^{3}$ ) do reservatório. A redução do nível da água foi tão alta que, para evitar o colapso no abastecimento público, fez-se necessário a instalação de bombas flutuantes para a captação de água e, foram tomadas medidas de contenção das retiradas de água, como, por exemplo, suspensão da descarga de perenização, racionamento do abastecimento urbano e proibição da irrigação, medidas que persistiram até o ano de 2016.

Sem previsão de novas recargas de água, a esperança mais viável para a recarga do manancial é a transposição das águas do Rio São Francisco, que chegaram ao reservatório em abril de 2017, com a conclusão da obra formada pelo Ministério Público da Paraíba (MPPB), Agência Nacional das Águas (ANA), Agência Executiva de Gestão das Águas do Estado da Paraíba (AESA), Ministério da Integração Nacional (MI) e representantes comerciais (BRITO, 2017). 


\subsection{RELAÇÃO DOS ANOS DE PRECIPITAÇÕES EXTREMAS E O VOLUME DO AÇUDE EPITÁCIO PESSOA}

A relação direta da precipitação com o volume de um açude é esperada, tendo em vista que a chuva é um dos principais mecanismos de aporte hídrico para um manancial. Entretanto, verifica- se que tal relação é defasada em relação ao tempo e depende do estado inicial do reservatório.

Os anos de 1979»80 foram secos, no entanto, os anos anteriores (19721978) variaram do normal a chuvoso e muito chuvoso. Diante disso, o volume do açude Epitácio Pessoa nesses anos secos reduziu, mas não foi considerada uma redução crítica, devido ao acúmulo de água proveniente das chuvas do período anterior. Isto também pode ser observado dois anos depois, em que 1982 e 1983 foram anos muito secos (Tabela 3), mas o volume do açude se manteve dentro de sua cota de abastecimento público, não se tornando uma situação preocupante.

Já nos anos de 1997 a 1999 percebe-se que há uma enorme queda no volume do açude (Figura 6-B e 6-C), chegando a atingir o volume de alerta do reservatório, apesar dos anos anteriores terem sido considerados normais. Esta situação requer uma análise mais detalhada para averiguar fatores como aumento da população, do uso para irrigação, diminuição da capacidade do reservatório devido ao assoreamento, dentre outros.

É importante lembrar que no período mencionado acima o açude presenciou o que foi chamado de pior crise hídrica da sua história até aquele momento, em que a CAGEPA decretou o primeiro racionamento na distribuição de água dos sistemas abastecidos pelo açude Epitácio Pessoa, durando 153 dias. O Ministério Público Estadual, através da Ação Cautelar no 570 Classe XII de 25 de fevereiro de 1999 suspendeu toda e qualquer irrigação na sub-bacia do Médio Curso do Rio Paraíba, e determinou que a água ali existente seria usada exclusivamente para o consumo humano das comunidades de Campina Grande, Boqueirão, Caturité, Queimadas, Pocinhos, além de outros municípios e, também para o consumo animal. Esta decisão está baseada na Art. 10 da Lei 9344/97, que determina o uso prioritário para abastecimento humano, em caso de escassez, ou falta de água (BRITO, 2008).

A partir do ano de 2004 inicia-se um novo ciclo de anos chuvosos e o açude consegue recuperar seus volumes de armazenamento, mas volta a entrar em colapso no ano de 2012, com uma sequência de anos secos e muitos secos (Tabela 3), dando início a uma nova crise hídrica que permeia até o presente ano (2016) e apresenta efeitos mais drásticos que a crise vivenciada no fim dos anos 90. Dessa forma, fica claro a relação da precipitação com o volume de um manancial, mas torna-se de difícil explicação em termos quantitativos, devido a influência dos fatores mencionados no texto. Já em termos qualitativos verificase uma relação direta, mas com necessidade de uma análise contínua.

\section{CONCLUSÕES}

Os resultados apresentados neste trabalho mostram uma visão geral histórica da situação de seca - redução das precipitações - no Nordeste brasileiro, mais precisamente nas sub-bacias do Alto Curso do Rio Paraíba e do Rio Taperoá, no estado da Paraíba, e, fornece informações úteis para a 
compreensão da distribuição e comportamento temporal da precipitação na região.

A alta variabilidade interanual da precipitação para a as duas sub-bacias na série histórica de 1972-2016 mostrou que durante os 45 anos de estudo houve seis anos muito chuvosos e seis anos muito secos, com precipitações extremas em relação à média da região. Já a variabilidade mensal da precipitação apontou que o período mais propício à drenagem de água e, consequentemente, para o armazenamento hídrico no reservatório do açude Epitácio Pessoa, compreende os seis primeiros meses do ano.

A partir da técnica dos quantis foi feita a classificação de toda a série em estudo, sendo assim um método de comprovação quanto a intensidade da precipitação nos doze anos extremos identificados. Foi possível identificar também que a quadra chuvosa da região não necessariamente possui a mesma classificação quantílica em relação à precipitação anual.

Em relação ao Açude Epitácio Pessoa, foi possível perceber que assim como há uma maior precipitação nos primeiros seis meses do ano, o volume do açude também apresenta seus maiores níveis nos mesmos meses, mostrando que a variação do volume do reservatório possui relação direta com o comportamento da precipitação da região. No entanto, em termos quantitativos, esta relação oferece apenas uma visão parcial do volume de água armazenado no açude, devido a influência direta e indireta de fatores/elementos como perda de água por evaporação, vazão afluente, vazão efluente, infiltração no solo, retirada de água para usos consuntivos e extravasamentos.

Dessa forma, através da metodologia utilizada foi possível identificar que o açude ultrapassou a sua capacidade máxima em um total de 16 anos, que foram classificados, a partir da técnica dos quantis, como anos chuvosos e muito chuvosos. Sendo assim, estes resultados sugerem que durante a série em estudo as oscilações no volume do reservatório podem ser explicadas também pelo clima característico e distribuição temporal da precipitação da região. No entanto, a vulnerabilidade hídrica presente também desencadeia impactos econômicos, sociais e ambientais, e isto foi agravado nos últimos anos, o que justifica a crise ocorrida entre os anos de 2012 a 2017 e a atual situação do abastecimento da população dependente do açude Epitácio Pessoa, que continua em estado de observação e passando por períodos de racionamento.

\section{REFERÊNCIAS}

AESA - Agência Executiva de Gestão das Águas do Estado da Paraíba. Volume dos Açudes. Disponível em: < http://www.aesa.pb.gov.br/aesawebsite/monitoramento/ultimos-volumes/>. Acesso em: 04 nov. 2019.

ALVES, J.M.B.; CAMPOS, J.N.B.; FERREIRA, F.F.; STUDART, T.M.C. As chuvas de janeiro/2004 no Nordeste do Brasil, suas características atmosféricas e seus impactos no recursos hídricos da região. In: Anais do $V$ Simpósio de Recursos Hídricos Do Nordeste. São Luiz, MA: ABRH, 2004.

ALBUQUERQUE, T. M. A. Seleção Multicriterial de Alternativas para o Gerenciamento da Demanda de Água na Escala de Bairro / Tatiana Máximo Almeida Albuquerque. Dissertação (Mestrado em Recursos hídricos). Universidade Federal de Campina Grande. Campina Grande, 2004. 150 p. 
ARAÚJO, L.E. Climatologia e Vulnerabilidade Socioeconômica e Ambiental da Bacia Hidrográfica do Rio Paraíba: Estudo de caso do Açude Epitácio Pessoa (Boqueirão). Tese (Programa de Pós-Graduação em Recursos Naturais). Universidade Federal de Campina Grande. Campina Grande, 2010.

BARRETO, J.F.; DANTAS NETO, J.; FARIAS, S.A.R. Avaliação socioeconômica e hídrica dos municípios da sub-bacia hidrográfica do rio Taperoá, PB. Qualit@s Revista Eletrônica, v.9, n.1, 2010.

BRITO, F. B. O conflito pelo uso da água do açude Epitácio Pessoa (Boqueirão) PB. Dissertação (Mestrado em Geografia). Universidade Federal da Paraíba, Programa de Pós- Graduação em Geografia. João Pessoa, 208f, 2008.

BRITO, V. C. Aplicação do Método de Árvore de Falhas ao processo de gestão da disponibilidade hídrica do reservatório Epitácio Pessoa. Monografia apresentada como Trabalho de Conclusão de Curso (Departamento de Engenharia Sanitária e Ambiental). Universidade Estadual da Paraíba. Campina Grande, 2017.

CAGEPA - Companhia de Águas e Esgoto da Paraíba. Cagepa - Sistemas de Abastecimento. Disponível em: <http://www.cagepa.pb.gov.br/sistemas-deabastecimento/>. Acesso em: 17 ago. 2016.

FERREIRA, A. G.; MELLO, N. G. S. Principais Sistemas Atmosféricos Atuantes sobre a Região Nordeste do Brasil e a Influência dos Oceanos Pacífico e Atlântico no Clima da Região. Revista Brasileira de Climatologia, v. 1, p. 15-26, 2005.

GALVÍNCIO, J. D. Balanço hídrico à superfície da bacia hidrográfica do açude Epitácio Pessoa, utilizando informações digitais do terreno. Tese de doutorado (Programa de pós- graduação em Recursos Naturais). Universidade Federal de Campina Grande. Campina Grande, 2005.

LUCENA, R. L.; PACHECO, C. O Cariri Paraibano: aspectos geomorfológicos, climáticos e de vegetação. Universidade Federal da Paraíba. In: VIII Simpósio Brasileiro de Climatologia Geográfica. 2008

MARENGO, J. A.; CUNHA, A. P.; ALVES, L. M. A seca de 2012-15 no semiárido do Nordeste do Brasil no contexto histórico. Climanálise, v.3, p. 1-6, 2016.

PAZ, A. R. Hidrologia Aplicada. Apostila da Disciplina Hidrologia Aplicada, UERGS - Caxias do Sul (RS), 2004.

PINKAYAN, S. Conditional probabilities of occurrence of wet and dry years over a large continental area. Forty-Collins. Colorado-USA: Hydrology Colorado State University, 1966.

PORTO, M. F. A.; PORTO, R. L. Gestão de Bacias Hidrográficas. Estudos Avançados, São Paulo, v.22, n.63, p.44-60, 2008 